\title{
REMEDIATION OF LEAD (II) AND MALACHITE GREEN FROM AQUEOUS SOLUTION USING PALM OIL FRUIT FIBRE
}

\author{
SHIN-LEEI OOI ${ }^{\mathrm{a}}$ and SIEW-TENG ONG ${ }^{\mathrm{a}, \mathrm{b}^{*}}$
}

\begin{abstract}
Oil palm fruit fibre (OPFF) was investigated for its potential and probability to remove heavy metal ion and dye from the aqueous solutions. Different operational parameters were studied under batch experiment. The effective $\mathrm{pH}$ to attain maximum adsorption of $\mathrm{MG}$ and $\mathrm{Pb}$ (II) by OPFF was around $\mathrm{pH} 4$ to 5 . The adsorption process was rapid at the beginning and slowly achieved equilibrium within 180 minutes and 120 minutes for MG and $\mathrm{Pb}(\mathrm{II})$, respectively. From the experimental result, the pseudo-second-order kinetic model provided better correlation compared to pseudo-first-order kinetic model with $\mathrm{R}^{2}>0.999$. Various isotherm equations, such as Langmuir, Freundlich, and BET isotherm models were used to analyze the adsorption isotherm result. The experimental data fitted well into Langmuir and BET isotherm models with $\mathrm{R}^{2}=0.996$ and 0.984 , respectively. The maximum adsorption capacity of OPFF from Langmuir equation was 41.67 and 10.10 $\mathrm{mg} / \mathrm{g}$ for $\mathrm{MG}$ and $\mathrm{Pb}(\mathrm{II})$, respectively. Besides, characterization study of OPFF which include point of zero charge $\left(\mathrm{pH}_{\mathrm{zpc}}\right)$, chemical modification on the functional group and surface morphology was also performed in this study.
\end{abstract}

Keywords: $\mathrm{Pb}(\mathrm{II})$, Malachite Green, Oil palm fibre, Adsorption, Batch study, Characterization study

\section{INTRODUCTION}

Industrial wastewater inevitably contains pollutants and if it is being discharged to the environment without a proper treatment, this can cause a serious environmental issue. The removal of dyes from industrial wastewater is one of the challenging environmental problems faced by many countries.

\footnotetext{
a Department of Chemical Science, Faculty of Science, Universiti Tunku Abdul Rahman, Jalan Universiti, Bandar Barat, 31900 Kampar, Perak, Malaysia.

b Centre for Biodiversity Research, Universiti Tunku Abdul Rahman, Jalan Universiti, Bandar Barat, 31900 Kampar, Perak, Malaysia.

*Corresponding author: ongst@utar.edu.my; ongst_utar@yahoo.com
} 
At present, there are many industries such as textile, dye manufacturing, paints, paper, carpet, leather, food, and tannery which using various types of dyes to colour their products. The worldwide annual production of dyes is about $7 \times 10^{5}$ tons and these dyes are discharged into waste streams by the aforementioned industries that cause negative impact to the environment and human health [1,2]. Besides from being highly coloured, studies have also shown that some dyes, dye precursors and their biotransformation products could be health threatening as they are toxic, mutagenic and carcinogenic in nature $[3,4]$. For instance, cationic dyes, which are widely used in colouring acrylic fibre are considered to be more toxic than other classes of dyes $[5,6]$. Malachite Green (MG), which is a type of cationic dye, has been selected as the adsorbate in this study because from the available scientific evidence, MG poses a serious health concerning issue. MG is known to be a multi-organ toxin and its potential carcinogenic, teratogenic, mutagenic and genotoxic properties has been well documented [4, 7-11].

Apart from coloured pollutant, heavy metal contamination is also a worrying issue in the control of environmental pollution. There are various routes in which heavy metals may enter the human body which include food, water, air, or absorption through the skin. The accumulation of heavy metals in the soft tissue can cause severe and adverse health problem to the nervous system, liver, and bones. In fact, there are several tragedies that occurred due to heavy metal contamination, which include Minamata disease (due to methyl mercury contamination) and another example is the endemic of "Itai-Itai" disease due to cadmium toxicity in Jitsu river of Japan.

Lead, $\mathrm{Pb}$ (II) is a heavy metal that is commonly found in industrial effluents due to their widespread usage in various industries such as leadacid batteries manufacturing, paints, ceramics, soldering, and electroplating. However, $\mathrm{Pb}(\mathrm{II})$ is a highly toxic heavy metal which will cause infertility, nervous system damage, anaemia, muscle and joint pains, diminishing $I Q$, kidney problem and high blood pressure to human [12]. The potential health hazard problems associated with lead has made it to be categorized as one of the top 20 hazardous substances under U.S. Environmental Protection Agency. According to Malaysia Environmental Quality (Sewage and Industrial Effluent) Regulation 1979, the lead content in effluent to be discharged is required to be not more than $0.1 \mathrm{mg} / \mathrm{L}$ [13].

Therefore, it is of utmost important to remove or at least reduce Malachite Green (MG) and $\mathrm{Pb}(\mathrm{II})$ content to the permitted level before discharging them into the open stream. As Malaysia is one of the world's largest producers and exporters of crude palm oil (CPO), there is about 3.0 million tons of oil palm empty fruit bunch (EFB) fibres being generated every year. Although these solid wastes have been used as solid fuel in boilers of 
processing mills, organic fertilizer, and reinforcing fibres for composite making [14], the utilization is still not fully maximized. Therefore, in this research, the feasibility of using oil palm fruit fibre as an adsorbent for heavy metals and dyes removal from aqueous solution was explored. It is hoped that this can reduces the amount of these solid wastes and also protect the environment for being polluted.

\section{RESULTS AND DISCUSSION}

FTIR Analysis. Figure 1 shows the infrared spectra of OPFF before and after adsorption of $\mathrm{Pb}(\mathrm{II})$. Table 1 summarizes the IR analysis for OPFF and the types of vibrations involved. It was found that the absorption band in this study was quite similar to the reported values from the literature.
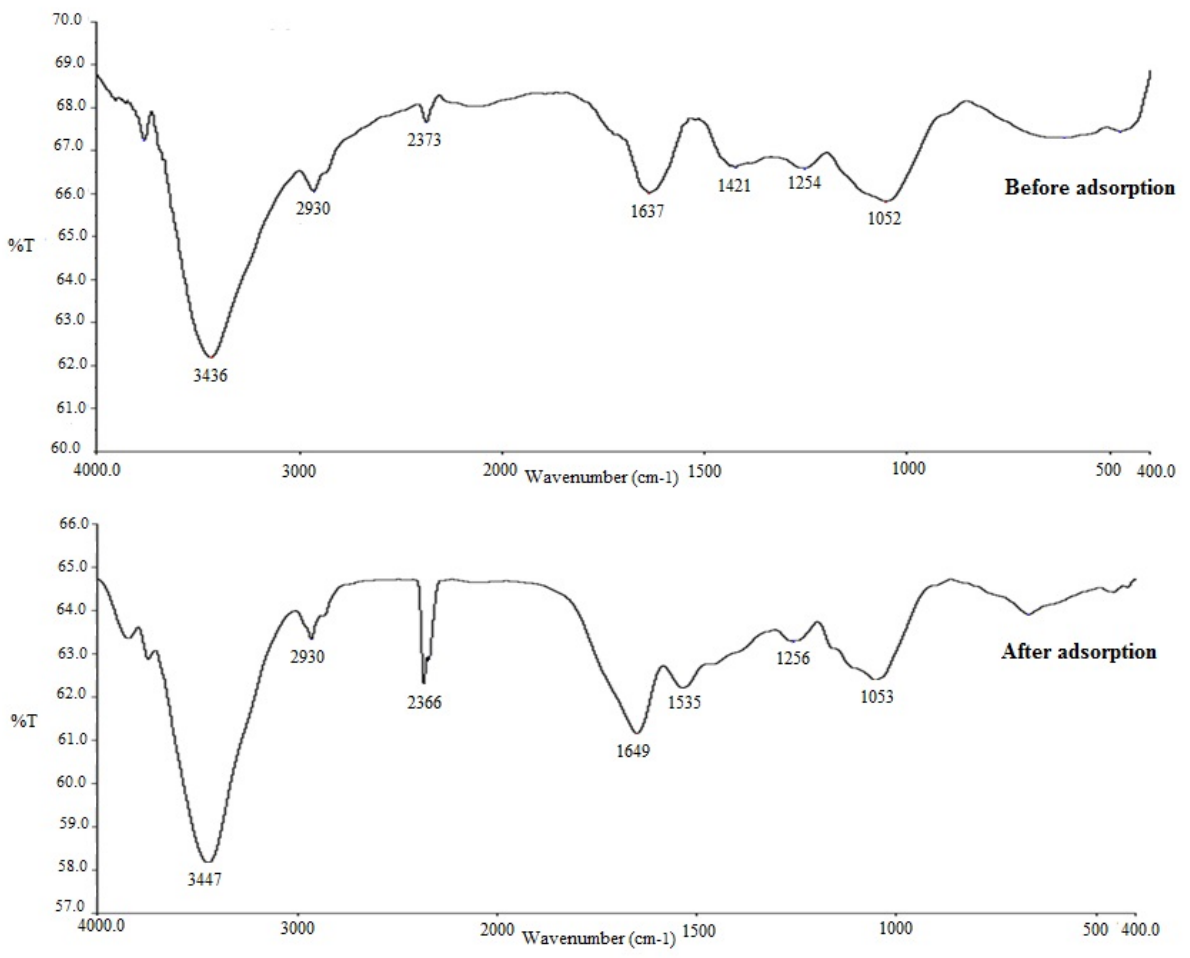

Figure 1. Infrared spectrum of OPFF before and after adsoption of $\mathrm{Pb}$ (II) 
The absorption of the $\mathrm{OH}$ group was found in the region of 3600-3200 $\mathrm{cm}^{-1}$. The peak around $2900 \mathrm{~cm}^{-1}$ is due to $\mathrm{C}-\mathrm{H}$ stretching whereas the one around $1050 \mathrm{~cm}^{-1}$ indicated the presence of lignin structure in OPFF. It was noticed that FTIR spectra of the OPFF (before and after adsorption), regardless of $\mathrm{MG}$ or $\mathrm{Pb}(\mathrm{II})$ are very similar to each other. This could be due to the limitations in the sensitivity of the instrument. Besides, as it has been postulated that the removal process mainly involved adsorption, which is a surface chemistry process, therefore, it is generally acceptable that the FTIR spectra before and after adsorption would not show much difference [15]. In addition, the FTIR spectra analysis of OPFF after $\mathrm{Pb}(\mathrm{II}$ ) adsorption (Table 2) and E-OPFF are also very similar to that of the unesterified material.

Table 1. FTIR spectral of OPFF before and after adsorption of MG

\begin{tabular}{|c|c|l|}
\hline \multicolumn{2}{|c|}{ Wave number $\mathbf{( c m}^{-1}$ ) } & \multicolumn{1}{|c|}{ Type of vibration } \\
\hline Before adsorption & After MG adsorption & -OH stretching vibrations \\
\hline 3764 & 3753 & $\begin{array}{l}- \text { OH stretching vibrations } \\
\text { (aromatic and carboxylic acid }\end{array}$ \\
\hline 3436 & 3436 & $\begin{array}{l}-\mathrm{CH} \text { stretching(methylene/ } \\
\text { methyl/methoxy) }\end{array}$ \\
\hline 2930 & 2930 & $-\mathrm{OH}$ stretch (carboxylic group) \\
\hline 2373 & 2370 & $\mathrm{C}=\mathrm{O}$ stretching \\
\hline 1637 & 1734 & $\begin{array}{l}-\mathrm{CH} \text { stretching(methylene/ } \\
\text { methyl/methoxy) }\end{array}$ \\
\hline 1421 & 1428 & $\mathrm{C}-\mathrm{O}$ from phenolic groups \\
\hline 1254 & 1259 & $\mathrm{C}-\mathrm{O}$ from phenolic groups \\
\hline 1052 & 1053 &
\end{tabular}

Table 2. FTIR spectral of OPFF before and after adsorption of $\mathrm{Pb}$ (II)

\begin{tabular}{|c|c|l|}
\hline \multicolumn{2}{|c|}{ Wave number $\mathbf{( c m}^{-1}$ ) } & \multicolumn{1}{|c|}{ Type of vibration } \\
\hline Before adsorption & After adsorption Pb(II) & \multicolumn{1}{c|}{$\begin{array}{l}\text { OH stretching vibrations } \\
\text { (aromatic and carboxylic acid }\end{array}$} \\
\hline 3436 & 3447 & $\begin{array}{l}\text {-CH stretching(methylene/ } \\
\text { methyl/methoxy) }\end{array}$ \\
\hline 2930 & 2930 & - OH stretch (carboxylic group) \\
\hline 2373 & $2366-2342$ & $\mathrm{C}=$ O stretching \\
\hline 1637 & 1649 & $\begin{array}{l}-\mathrm{CH} \text { stretching(methylene/ } \\
\text { methyl/methoxy) }\end{array}$ \\
\hline 1421 & 1535 & C-O from phenolic groups \\
\hline 1254 & 1256 & C-O from phenolic groups \\
\hline 1052 & 1053 &
\end{tabular}


Scanning Electron Microscopy (SEM). Scanning electron microscope was used to study the surface morphology of OPFF. Figures $2 a$ and $2 b$ show the SEM images of original OPFF and OPFF after adsorption. From the SEM micrographs, the present of the lignin structure was evident and this was still maintained after the adsorption process. It was also observed that OPFF belongs to a non-porous material, due to the absence of pores and cavities.

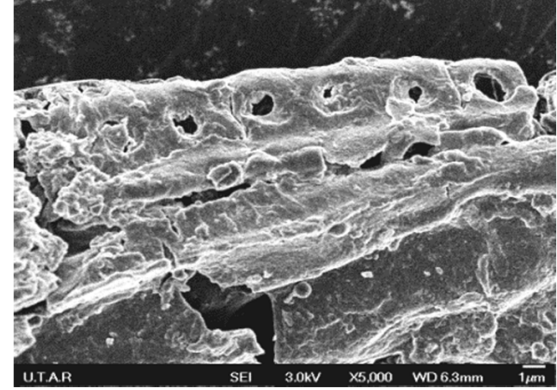

a

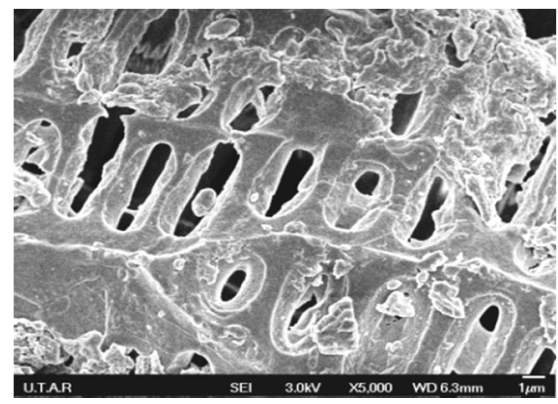

b

Figure 2. SEM micrograph of OPFF (a) before adsorption (b) after adsorption

Determination of $\mathrm{pH}$ point of zero charge $\left(\mathrm{pH}_{p z c}\right)$. The $\mathrm{pH}_{\mathrm{zpc}}$ of the oil palm fruit fibre was measured by using the mass titration method [16]. The point of zero charge is the $\mathrm{pH}$ value where the net total particle charge is zero [17]. This parameter is very important to describe the variable-charge surface which is either positive or negative of adsorbent. Based on the result, the $\mathrm{pH}_{\mathrm{pzc}}$ of OPFF was determined to be around $\mathrm{pH} 5$. When the $\mathrm{pH}$ of the solution is above $\mathrm{pH}_{\mathrm{pzc}}$, the surface charge of the OPFF will become negative. Meanwhile, the surface charge of OPFF will become positive when the $\mathrm{pH}$ of the solution is below $\mathrm{pH} \mathrm{pzc}_{\mathrm{pc}}$.

Effect of $\mathrm{pH}$. Figure 3 shows the percentage uptake of $\mathrm{MG}$ and $\mathrm{Pb}(\mathrm{II})$ versus $\mathrm{pH}$. The percentage uptake was the lowest at $\mathrm{pH} 2$. As the $\mathrm{pH}$ was increased to $\mathrm{pH} 3$, the percentage uptake of MG increased drastically to 99.02 $\%$. Thereafter, the adsorption uptake remains nearly constant in the $\mathrm{pH}$ range of 3-8. As for $\mathrm{Pb}$ (II) uptake, the effect of $\mathrm{pH}$ was studied in the range of 2-5 because $\mathrm{Pb}(\mathrm{II})$ form precipitate at $\mathrm{pH}$ above 5 . Similar to the trend observed in MG uptake, the lowest uptake of $\mathrm{Pb}$ (II) was also recorded at $\mathrm{pH} 2$. Thereafter, it increased sharply to $94.67 \%$ at $\mathrm{pH}$ 3. The maximum $\mathrm{Pb}$ (II) uptake is 97.11 $\%$ and obtained at $\mathrm{pH} 5$. Although the $\mathrm{pH}_{\mathrm{pzc}}$ of OPFF was around $\mathrm{pH} 5$, an appreciable amount of adsorbates can be removed below $\mathrm{pH}_{\mathrm{pzc}}$ and this could be attributed by the simultaneous occurrence of different kinds of interactions such as entrapment, ion-exchange, hydrophobic attraction and physical adsorption [6]. Similar adsorption pattern has been reported in the uptake of cadmium ions by various fruit peel wastes [18]. 
It is suggested that at low $\mathrm{pH}$, the carboxyl and hydroxyl groups on the surface of OPFF were predominantly protonated, thus inhibiting the uptake of $M G$ and $\mathrm{Pb}(\mathrm{II})$. Besides, hydrogen ion, $\mathrm{H}^{+}$will also compete with $\mathrm{MG}$ and $\mathrm{Pb}$ (II) for the adsorption sites. The adsorption of $\mathrm{MG}$ and $\mathrm{Pb}$ (II) are not favourable in acidic medium because of the electrostatic repulsion. As the $\mathrm{pH}$ increased, the adsorption became favourable due to the deprotonation of hydroxyl (Ar-O) and carboxyl group (-COO-) on the surface of OPFF. This will increase the electrostatic attraction between negative surface charge of OPFF and the cationic MG and $\mathrm{Pb}$ (II). The \% uptake of MG and $\mathrm{Pb}$ (II) by using OPFF shows that it is highly dependent on solution $\mathrm{pH}$. Because the maximum adsorption of the $\mathrm{MG}$ and $\mathrm{Pb}$ (II) occurs around $\mathrm{pH} 4-5$, therefore, the following parameters were carried out at $\mathrm{pH} 4$ for both $\mathrm{MG}$ and $\mathrm{Pb}(\mathrm{II})$.

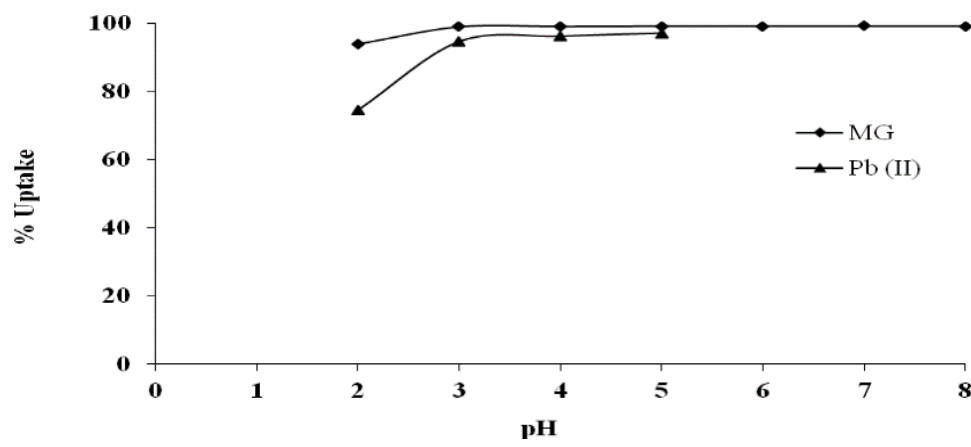

Figure 3. Effect of $\mathrm{pH}$ on the uptake of $\mathrm{MG}$ and $\mathrm{Pb}(\mathrm{II})$ by OPFF

The carboxyl groups in OPFF were esterified using acidic methanol method [19] to verify the importance role of carboxyl groups in the adsorption process of $M G$ and $\mathrm{Pb}(\mathrm{II})$. The results on the percentage uptake of $\mathrm{MG}$ and $\mathrm{Pb}$ (II) showed that native OPFF has higher percentage uptake as compared to e-OPFF. This is because this type of modification will render the carboxyl groups unavailable for the binding and result in a reduction in the adsorption site for MG and $\mathrm{Pb}(\mathrm{II})$. The percentage uptake of $\mathrm{Pb}$ (II) and MG by using the native OPFF are $95.98 \%$ and $99.10 \%$, respectively, whereas the uptake of $\mathrm{Pb}(\mathrm{II})$ and $\mathrm{MG}$ by using esterified OPFF are only $43.98 \%$ and $95.62 \%$, respectively.

Effect of initial concentrations and contact time. The main purpose to study the effect of initial concentrations and contact time is to determine the equilibrium time for maximum adsorption. Figures 4 and 5 show the effect of initial concentrations and contact time on the uptake of $\mathrm{MG}$ and $\mathrm{Pb}(\mathrm{II})$, respectively by using OPFF. Different concentrations were used for MG and $\mathrm{Pb}$ (II) due to the different requirement set by local regulation. 
Both results indicated that the percentage uptake of $\mathrm{MG}$ and $\mathrm{Pb}(\mathrm{II})$ decreased gradually with increasing concentrations. At the first 30 minutes, the uptake rate increased rapidly and thereafter the dye and metal uptake rate become slower and finally reached equilibrium at 120 minutes for both adsorbates.

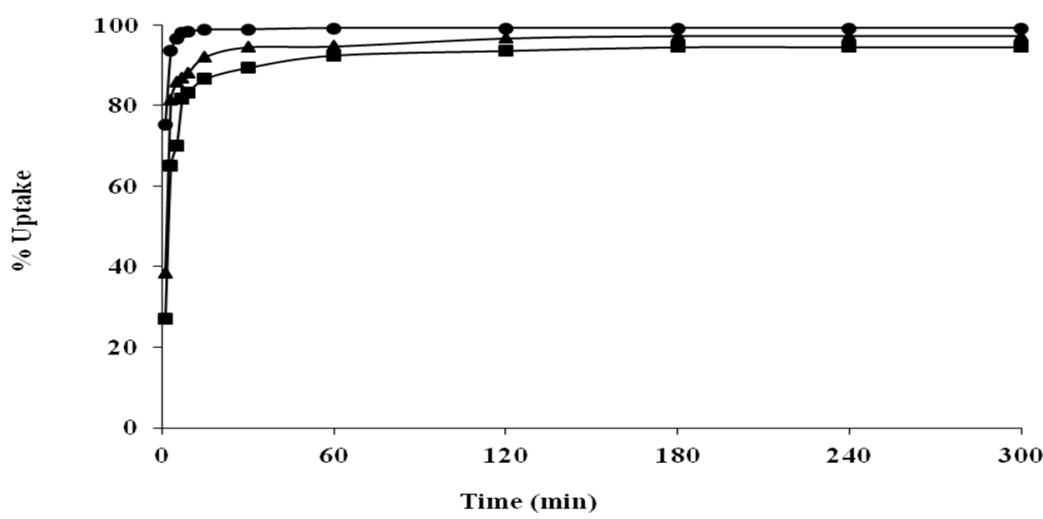

Figure 4. Effect of initial concentrations and contact time on the adsorption of MG by OPFF. $\bullet, \mathbf{\Lambda},-100,150$ and $200 \mathrm{mg} / \mathrm{L}$ of MG

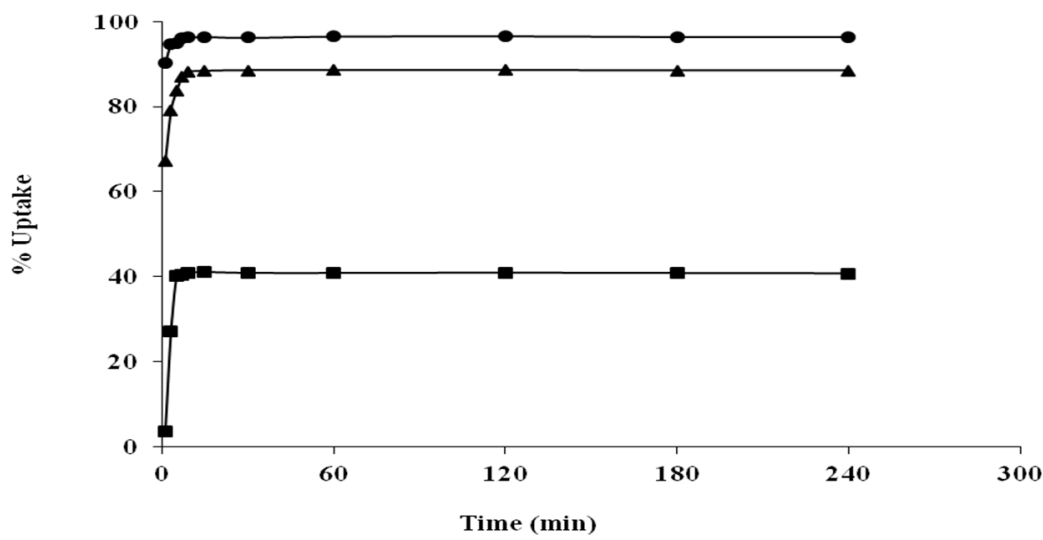

Figure 5. Effect of initial concentrations and contact time on the adsorption of $\mathrm{Pb}$ (II) by OPFF. •, $\mathbf{\Lambda},-20,50$ and $80 \mathrm{mg} / \mathrm{L}$ of $\mathrm{Pb}(\mathrm{II})$

The fast uptake for initial stage is associated with the huge number of vacant sites on the OPFF at the beginning. After the adsorption takes place, the uptake rate becomes slower and required longer time to achieve equilibrium because the active site of OPFF was saturated with adsorbates. 
The results showed that the time needed to achieve equilibrium was independent of the initial dye and heavy metal concentrations.

Kinetic studies. The experimental data were examined using different equations, pseudo-first-order [20] and pseudo-second-order kinetics [21] in order to identify which model will be more suitable to describe the system under study. Besides, this can also be used to explain the rate-controlling steps in the adsorption process.

The linear equation of pseudo-first-order (Eq. 1) [20] and pseudosecond-order (Eq. 2) [21] can be expressed as follows:

$$
\log \left(q_{e}-q_{t}\right)=\log q_{e}-\frac{k_{1}}{2.303} t
$$

and

$$
\frac{\mathrm{t}}{\mathrm{q}_{\mathrm{t}}}=\frac{1}{\mathrm{~h}}+\frac{1}{\mathrm{q}_{\mathrm{e}}} \mathrm{t}
$$

where $\mathrm{q}_{\mathrm{e}}=$ the amount of $\mathrm{MG} / \mathrm{Pb}(\mathrm{II})$ adsorbed at equilibrium $(\mathrm{mg} / \mathrm{g}), \mathrm{q}_{\mathrm{t}}=$ the amount of $\mathrm{MG} / \mathrm{Pb}(\mathrm{II})$ adsorbed at time $\mathrm{t}(\mathrm{mg} / \mathrm{g}), \mathrm{k}_{1}=$ the rate constant of pseudo-first-order adsorption $(1 / \mathrm{min}), \mathrm{h}\left(\mathrm{k}_{2} \mathrm{q}_{\mathrm{e}}{ }^{2}\right)=$ the initial adsorption rate $\left(\mathrm{mg} / \mathrm{g} \mathrm{min}\right.$ ) and $\mathrm{k}_{2}=$ the rate constant of pseudo-second-order kinetics ( $\mathrm{g} / \mathrm{mg}$ $\min )$.

Based on the results obtained, the theoretical $\mathrm{q}_{\mathrm{e}}$ values generated by pseudo-first-order kinetic model equation gave unreasonable values compared to those determined experimentally (Table 3 ). Besides, the $R^{2}$ of the pseudofirst-order was relatively low as compared to pseudo-second-order model for $M G$ and $\mathrm{Pb}(\mathrm{II})$. This result indicates that the adsorption process of both MG and $\mathrm{Pb}$ (II) onto OPFF is better explained via pseudo-second-order model which is based on the assumption that the rate-limiting step may be due to chemisorptions, which involve valency force through sharing and exchanging of electron between adsorbent and adsorbate [21]. The applicability of pseudosecond-order model in the adsorption of dyes or heavy metal ions have also been reported in other works involving $\mathrm{H}_{2} \mathrm{SO}_{4}$ activated Salvadora persica [2], alginate-coated perlite beads [4], AC prepared from Amygdalus scoparia [8], corn cob [15], rambutan peel [22], pigeon pea hulls [23] and chitin hydrogels [24]. 
REMEDIATION OF LEAD (II) AND MALACHITE GREEN FROM AQUEOUS SOLUTION USING PALM ...

Table 3. Pseudo-first-order and pseudo-second-order kinetic model parameters for different initial $\mathrm{MG}$ and $\mathrm{Pb}(\mathrm{II})$ concentrations

\begin{tabular}{|c|c|c|c|c|c|c|c|}
\hline \multirow{2}{*}{$\begin{array}{c}\text { Initial MG } \\
\text { concentration } \\
(\mathrm{mg} / \mathrm{L})\end{array}$} & \multirow[t]{2}{*}{$\begin{array}{l}q_{e, \text { exp }} \\
(\mathrm{mg} / \mathrm{g})\end{array}$} & \multicolumn{3}{|c|}{\begin{tabular}{|c|}
$\begin{array}{c}\text { Pseudo-first-order kinetic } \\
\text { model }\end{array}$ \\
\end{tabular}} & \multicolumn{3}{|c|}{$\begin{array}{c}\text { Pseudo-second-order kinetic } \\
\text { model }\end{array}$} \\
\hline & & $\begin{array}{c}q_{e, \text { cal }} \\
(\mathrm{mg} / \mathrm{g})\end{array}$ & $\begin{array}{c}\boldsymbol{k}_{1} \\
(1 / \mathrm{min})\end{array}$ & $R^{2}$ & $\begin{array}{l}q_{\mathrm{e}, \mathrm{cal}} \\
(\mathrm{mg} / \mathrm{g})\end{array}$ & $\begin{array}{c}\boldsymbol{k}_{\mathbf{2}} \\
(\mathrm{g} / \mathrm{mg} \min )\end{array}$ & $R^{2}$ \\
\hline 100 & 19.916 & 0.5058 & 0.05067 & 0.677 & 20.000 & 0.41670 & 1 \\
\hline 150 & 30.708 & 4.6666 & 0.02764 & 0.768 & 31.250 & 0.03103 & 1 \\
\hline 200 & 39.740 & 9.1201 & 0.02994 & 0.795 & 40.000 & 0.01524 & 1 \\
\hline \multicolumn{8}{|l|}{$\begin{array}{c}\text { Initial Pb (II) } \\
\text { concentration } \\
(\mathrm{mg} / \mathrm{L})\end{array}$} \\
\hline 20 & 4.369 & 0.4875 & 0.4859 & 0.950 & 4.386 & 7.4260 & 1 \\
\hline 50 & 8.935 & 2.6242 & 0.3823 & 0.943 & 9.009 & 0.7247 & 1 \\
\hline 80 & 6.552 & 15.6675 & 0.8360 & 0.937 & 6.623 & 0.0857 & 0.998 \\
\hline
\end{tabular}

In view of the suitability of the adsorption process to be described by pseudo-second-order kinetic model, the values of $\mathrm{q}_{\mathrm{e}}, \mathrm{k}_{2}$, and $\mathrm{h}$ against $\mathrm{C}_{\mathrm{o}}$ in the corresponding linear plots of the pseudo- second-order equation were regressed to obtain expressions for these values in terms of the initial dye concentration. These parameters could be expressed as a function of $\mathrm{C}_{0}$ for $\mathrm{MG}$ and $\mathrm{Pb}(\mathrm{II})$ as follows [25]:

$$
\begin{gathered}
\mathrm{q}_{\mathrm{e}}=\frac{\mathrm{C}_{\mathrm{o}}}{\mathrm{A}_{\mathrm{q}} \mathrm{C}_{\mathrm{o}}+\mathrm{B}_{\mathrm{q}}}=\frac{\mathrm{C}_{\mathrm{o}}}{\mathrm{A}_{\mathrm{k}} \mathrm{C}_{\mathrm{o}}+\mathrm{B}_{\mathrm{k}}} \\
\mathrm{h}=\frac{\mathrm{C}_{\mathrm{o}}}{\mathrm{A}_{\mathrm{h}} \mathrm{C}_{\mathrm{o}}+\mathrm{B}_{\mathrm{h}}}
\end{gathered}
$$

where $A_{q}, B_{q}, A_{k}, B_{k}, A_{h}$ and $B_{h}$ are constant for the respective equations and obtained through regression from the linear plots. The generalized predictive models for $\mathrm{MG}$ and $\mathrm{Pb}(\mathrm{II})$ adsorbed at any contact time and initial dye concentrations within the given range with relationship of $\mathrm{q}_{t}, \mathrm{C}_{o}$ and $\mathrm{t}$ can be expressed as follow:

$$
\mathrm{q}_{\mathrm{t}}=\frac{\mathrm{C}_{\mathrm{o}} \mathrm{t}}{\mathrm{A}_{\mathrm{h}} \mathrm{C}_{\mathrm{o}}+\mathrm{B}_{\mathrm{h}}+\left(\mathrm{A}_{\mathrm{q}} \mathrm{C}_{\mathrm{o}}+\mathrm{B}_{\mathrm{q}}\right) \mathrm{t}}
$$


By substituting the calculated constant values, the theoretical model for MG-OPFF system could be expressed by the following equations:

$$
\mathrm{q}_{\mathrm{t}}=\frac{\mathrm{C}_{\mathrm{o}} \mathrm{t}}{0.074 \mathrm{C}_{\mathrm{o}}-6.852+\left(0.001 \mathrm{C}_{\mathrm{o}}+4.833\right) \mathrm{t}}
$$

whereas for $\mathrm{Pb}(\mathrm{II})$-OPFF system, it can be represented by Eq. 9 .

$$
\mathrm{q}_{\mathrm{t}}=\frac{\mathrm{C}_{\mathrm{o}} \mathrm{t}}{0.255 \mathrm{C}_{\mathrm{o}}-6.225+\left(0.086 \mathrm{C}_{\mathrm{o}}+3.023\right) \mathrm{t}}
$$

Figures 6 and 7 show the comparison of the predicted theoretical values and experimental data for $\mathrm{MG}$ and $\mathrm{Pb}(\mathrm{II})$ adsorption, respectively by OPFF. The result indicated that the pseudo-second-order provided a good prediction for the amounts of $\mathrm{MG}$ and $\mathrm{Pb}$ (II) adsorbed onto OPFF, but not at higher concentration. The deviation observed at higher concentration could be related with the poor $R^{2}$ of the linear graph $k_{2}, h$, and $q_{e}$ against $C_{0}$.

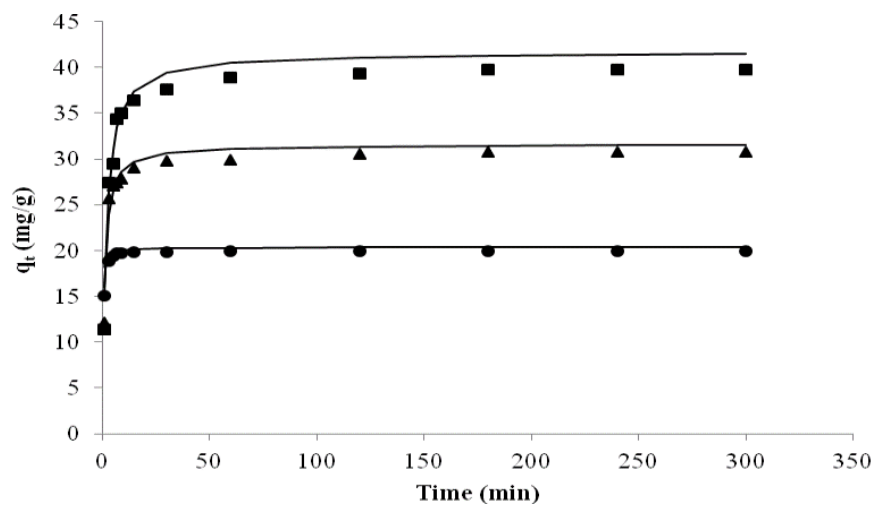

Figure 6. Comparison plots between the measured and pseudo second-order

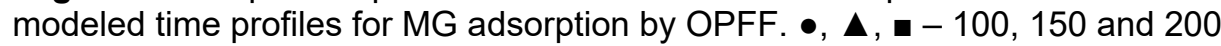
$\mathrm{mg} / \mathrm{L}$ of MG; symbol = experimental data, line = pseudo second order model.

Adsorption Isotherm. The adsorption isotherm is useful in providing the information about the adsorption properties, equilibrium data, and interaction between the adsorbate and adsorbent with a homogenous or heterogeneous surface. In order to obtain the equilibrium relationships between the adsorbent and adsorbate, Langmuir, Freundlich, and Brunauer-Emmett-Teller (BET) isotherm models [26-28] were being employed to determine and analyze the adsorption behaviour of $\mathrm{MG}$ and $\mathrm{Pb}$ (II) on OPFF. 


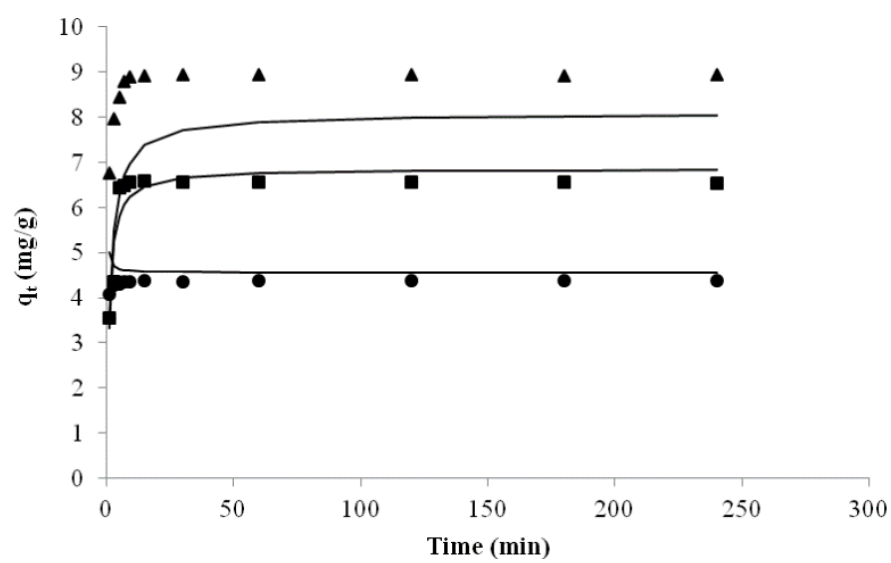

Figure 7. Comparison plots between the measured and pseudo second-order modeled time profiles for $\mathrm{Pb}$ (II) adsorption by OPFF. $\bullet, \mathbf{\Lambda}, \mathbf{-}-20,50$ and $80 \mathrm{mg} / \mathrm{L}$ of $\mathrm{Pb}(\mathrm{II})$; symbol $=$ experimental data, line $=$ pseudo second order model.

The Langmuir isotherm is based on the assumption that adsorbate is forming monolayer coverage on the adsorbent surface and the adsorbent surface consists of homogenous sites with constant adsorption energy. When the dye or heavy metal ions fill up the vacant site of adsorbent, the adsorption process will no longer be favourable. Besides that, there are no interactions between the neighbouring adsorbed molecules; each site can adsorb only one molecule and no phase transitions. The linear form of the Langmuir isotherm can be expressed by the following equation [26]:

$$
\frac{\mathrm{C}_{\mathrm{e}}}{\mathrm{q}_{\mathrm{e}}}=\frac{1}{\mathrm{q}_{\max }} \mathrm{C}_{\mathrm{e}}+\frac{1}{\mathrm{~K}_{\mathrm{L}} \mathrm{q}_{\max }}
$$

where $C_{e}=$ equilibrium concentration of the adsorbate $(\mathrm{mg} / \mathrm{l}), \mathrm{q}_{\mathrm{e}}=$ amount of adsorbate adsorbed at equilibrium $(\mathrm{mg} / \mathrm{g}), \mathrm{q}_{\max }=$ maximum adsorption capacity $(\mathrm{mg} / \mathrm{g}), \mathrm{K}_{\mathrm{L}}=$ constant related to the energy of the adsorbent $(\mathrm{l} / \mathrm{mg})$.

The coefficient of determination, $R^{2}$ is 0.996 and 0.984 , respectively for the linear plot of $M G$ and $\mathrm{Pb}(\mathrm{II})$ adsorbed on OPFF. This result indicates the applicability of Langmuir isotherm to the adsorption of $\mathrm{MG}$ and $\mathrm{Pb}(\mathrm{II})$ by OPFF. Therefore, it is assumes that a monolayer coverage of adsorbate occurs over the adsorbent's surface with constant adsorption energy. The constant values $\mathrm{K}_{\mathrm{L}}$ and $\mathrm{q}_{\mathrm{e}}$ could be obtained from the intercept and the slope of the plots, respectively. The value maximum adsorption capacity, $\mathrm{q}_{\mathrm{e}}$ is $41.67 \mathrm{mg} / \mathrm{g}$ and the value of $K_{L}$ is 0.73 . The Langmuir isotherm values for the adsorption of $M G$ and $\mathrm{Pb}(\mathrm{II})$ were shown in Table 4. 
As for Freundlich isotherm, it involved physicochemical adsorption on the heterogeneous surface of the adsorbent. This isotherm can be used to describe the non-ideal adsorption that is more flexible and do not indicate an adsorption limit. The Freundlich isotherm can be expressed by the following equation [27]:

$$
\mathrm{q}_{\mathrm{e}}=\mathrm{K}_{\mathrm{f}} \mathrm{C}_{\mathrm{e}}{ }^{1 / \mathrm{n}}
$$

The equation above can be linearized by taking logarithm of both sides. The linear equation of Freundlich isotherm is shown as follow:

$$
\log \mathrm{q}_{\mathrm{e}}=\log \mathrm{K}_{\mathrm{F}}+\frac{1}{\mathrm{n}} \log \mathrm{C}_{\mathrm{e}}
$$

where $\mathrm{K}_{\mathrm{f}}=$ Freundlich constant for adsorption capacity, $\mathrm{n}=$ Freundlich constant for intensity, $\mathrm{q}_{\mathrm{e}}=$ Amount of dye and metal adsorbed at equilibrium $(\mathrm{mg} / \mathrm{g}), \mathrm{C}_{\mathrm{e}}=$ Equilibrium concentration of the dye and metal $(\mathrm{mg} / \mathrm{L})$

A linear plot of $\log q_{e}$ versus $\log C_{e}$ was obtained and the values of $K_{f}$ and $\mathrm{n}$ can be determined from the intercept and slope of the linear plot, respectively. The Freundlich isotherm values for the adsorption of MG and $\mathrm{Pb}$ (II) were presented in Table 4. Based on the $\mathrm{R}^{2}$ values, Langmuir isotherm was found to be a more suitable model to describe the adsorption of both MG and $\mathrm{Pb}(\mathrm{II})$ on OPFF compared to Freundlich isotherm.

Table 4. Langmuir, Freundlich, and BET constants for the adsorption of $\mathrm{MG}$ and $\mathrm{Pb}(\mathrm{II})$ by OPFF

\begin{tabular}{|c|c|c|c|c|c|c|c|c|c|}
\hline Adsorbate & \multicolumn{3}{|c|}{ Langmuir } & \multicolumn{3}{c|}{ Freundlich } & \multicolumn{3}{c|}{ BET } \\
\hline & $\begin{array}{c}\mathrm{q}_{\max } \\
(\mathrm{mg} / \mathrm{g})\end{array}$ & $\begin{array}{c}\mathrm{K}_{\mathrm{L}} \\
(\mathrm{L} / \mathrm{mg})\end{array}$ & $\mathrm{R}^{2}$ & $\mathrm{~K}_{\mathrm{f}}$ & $\mathrm{n}$ & $\mathrm{R}^{2}$ & $\mathrm{~K}_{\mathrm{B}}$ & $\begin{array}{c}\mathrm{q}_{\max } \\
(\mathrm{mg} / \mathrm{g})\end{array}$ & $\mathrm{R}^{2}$ \\
\hline $\mathrm{MG}$ & 41.67 & 0.73 & 0.996 & 17.14 & 2.29 & 0.986 & 13320 & 41.66 & 0.996 \\
\hline $\mathrm{Pb}(\mathrm{II})$ & 10.10 & 1.06 & 0.984 & 4.59 & 2.22 & 0.763 & 563782 & 10.10 & 0.984 \\
\hline
\end{tabular}

BET isotherm is extended based on the Langmuir isotherm which assumes that the adsorbent surface is composed of fixed individual sites, and molecules can be adsorbed to a thickness of more than one layer, on the surface of the adsorbent. The linear form of BET equation can be written as follows [28]:

$$
\frac{\mathrm{C}_{\mathrm{e}}}{\left(\mathrm{C}_{\mathrm{s}}-\mathrm{C}_{\mathrm{e}}\right) \mathrm{q}}=\frac{1}{\mathrm{~K}_{\mathrm{B}} \mathrm{q}_{\max }}+\left(\frac{\mathrm{K}_{\mathrm{B}}-1}{\mathrm{~K}_{\mathrm{B}} \mathrm{q}_{\max }}\right)\left(\frac{\mathrm{C}_{\mathrm{e}}}{\mathrm{C}_{\mathrm{s}}}\right)
$$

where $C_{s}=$ Saturation concentration of solute $(\mathrm{mg} / \mathrm{L}), K_{B}=$ Constant describing the energy of interactions between the solute and the adsorbent surface, $\mathrm{q}_{\max }=$ Amount of solute in forming a complete monolayer $(\mathrm{mg} / \mathrm{g})$ 
The BET isotherm values for the adsorption of $M G$ and $\mathrm{Pb}(\mathrm{II})$ were presented in Table 4 and from the result, it is evident that the equilibrium adsorption also fitted well into the BET isotherm. The applicability of both Langmuir and BET isotherm suggest that the adsorbate forming a monolayer on the surface of adsorbent and the adsorption of the adsorbate was extended beyond monolayer coverage.

\section{CONCLUSIONS}

This study identified OPFF, which is an agricultural waste could be used as the potential low-cost adsorbent to remove the MG and $\mathrm{Pb}(\mathrm{II})$ from aqueous solution. According to the result obtained, the $\mathrm{pH}_{\mathrm{pzc}}$ of OPFF is around $\mathrm{pH}$ 5. The percentage uptake of $\mathrm{MG}$ and $\mathrm{Pb}$ (II) decreased when using the esterified OPFF, suggesting the involvement of $\mathrm{COOH}$ group in the adsorption process. The effective $\mathrm{pH}$ to attain maximum adsorption of $\mathrm{MG}$ and $\mathrm{Pb}$ (II) were around $\mathrm{pH} 4$ to 5 . A rapid uptake was observed at the beginning of the process and the contact time needed for the attainment of equilibrium was 3 hours for MG and 2 hours for the $\mathrm{Pb}$ (II). It was found that the pseudo-secondorder kinetic model provides a better $\mathrm{R}^{2}$ as compared pseudo-first-order kinetic model, which suggested the chemisorption of $M G$ and $\mathrm{Pb}$ (II) onto OPFF. Finally, Langmuir and BET isotherm appeared to be the most appropriate models to illustrate the adsorption process, with the high $\mathrm{R}^{2}$ which are 0.996 and 0.984 for $\mathrm{MG}$ and $\mathrm{Pb}(\mathrm{II})$, respectively for both isotherm. The maximum adsorption capacities of OPFF obtained from Langmuir isotherm are 41.67 $\mathrm{mg} / \mathrm{g}$ and $10.10 \mathrm{mg} / \mathrm{g}$ for $\mathrm{MG}$ and $\mathrm{Pb}(\mathrm{II})$, respectively.

\section{EXPERIMENTAL SECTION}

\section{Preparation of $\mathrm{MG}$ and $\mathrm{Pb}(\mathrm{II})$ stock solution}

Synthetic dye solution of $M G(C l=42,000, M W=929.02 \mathrm{~g} / \mathrm{mol}$, chemical formula $=\mathrm{C}_{46} \mathrm{H}_{50} \mathrm{~N}_{4} \cdot 3 \mathrm{C}_{2} \mathrm{H}_{2} \mathrm{O}_{4}, \lambda_{\max }=618 \mathrm{~nm}$, Sigma-Aldrich Pte. Ltd) was used as adsorbate in this study. As for $\mathrm{Pb}(\mathrm{II})$, the synthetic heavy metal solution was prepared from A.R. grade $\mathrm{Pb}\left(\mathrm{NO}_{3}\right)_{2}$. All the chemicals were used as received without any further purification. A $1000 \mathrm{mg} / \mathrm{L}$ of stock solution was prepared for both adsorbates and subsequently diluted when necessary.

\section{Preparation of adsorbent}

The oil palm fruit fibre (OPFF) was used as adsorbent in this study and it was collected from a Batu Kawan palm oil plantation in Penang, Malaysia. It was washed several times with tap water and rinsed with distilled 
water to remove the dust and dirt on the surface of fibre. Then, it was dried under the sunlight for a few days. The dried OPFF was ground by using the mortar and pestle and sieved to obtain the particle sizes ranging from 0.5 $1 \mathrm{~mm}$ and stored in dry plastic container for further use.

\section{Characterisation of adsorbent}

\section{Fourier Transform Infrared Spectrophotometer (FTIR)}

The functional groups present on OPFF were determined using PerkinElmer System 2000 FT-IR Spectrometer. The OPFF sample disk was prepared by mixing the dried adsorbent with $\mathrm{KBr}$. The spectra of oil palm fruit fibre before and after undergoing adsorption of $\mathrm{MG}$ and $\mathrm{Pb}(\mathrm{II})$ were recorded.

\section{Scanning Electron Microscopy (SEM)}

Scanning electron microscope (SEM) was used to examine the surface morphology of OPFF before and after adsorption process. The surface morphology was studied using FESEM JSM 6701F (JEOL). Before the sample was analyzed, the prepared pellet was coated with a thin layer of gold to prevent the occurrence of charging effect.

\section{Batch experiments}

Batch experiments were carried out at room temperature $\left(25 \pm 2^{\circ} \mathrm{C}\right)$. The batch adsorption experiments were performed in duplicate and the results given are the means with a relative standard deviation (RSD) of less than $5 \%$. Adsorption experiments were carried out by agitating $0.10 \mathrm{~g}$ of adsorbent in 20 $\mathrm{mL}$ of $\mathrm{MG}$ or $\mathrm{Pb}(\mathrm{II})$ solutions in a centrifuge tube at $150 \mathrm{rpm}$ on an orbital shaker for 4 hours to allow the attainment of equilibrium. After that, the adsorbent-adsorbate mixture was centrifuged at $3000 \mathrm{rpm}$ for 2 minutes for phase separation. For MG, the supernatant was used to analyze for its dye concentration by using the Perkin Elmer UV-Vis spectrophotometer. All the measurement was made at the wavelength corresponding to its maximum absorption, $\lambda_{\max }=618 \mathrm{~nm}$. As for $\mathrm{Pb}(\mathrm{II})$, the final concentrations of the metal ions were analyzed by using the Perkin Elmer Atomic Absorption Spectrophotometer (AAS).

The percentage uptake and the amount of $\mathrm{MG}$ and $\mathrm{Pb}(\mathrm{II})$ adsorbed (q) was determined by using the following equations:

$$
\% \text { Uptake }=\frac{\mathrm{C}_{\mathrm{o}}-\mathrm{C}_{\mathrm{e}}}{\mathrm{C}_{\mathrm{o}}} \times 100 \%
$$


REMEDIATION OF LEAD (II) AND MALACHITE GREEN FROM AQUEOUS SOLUTION USING PALM ...

$$
q=C_{o}-C_{e} \times \frac{V}{M}
$$

where $\mathrm{C}_{\mathrm{o}}$ and $\mathrm{C}_{\mathrm{i}}$ are the initial and equilibrium concentration of $\mathrm{MG}$ or $\mathrm{Pb}(\mathrm{II})$, respectively, $\mathrm{V}=$ the volume of the solution $(\mathrm{L})$ and $\mathrm{W}=$ the mass of the adsorbent (g).

For the effect of $\mathrm{pH}$, a series of $50 \mathrm{mg} / \mathrm{L}$ of MG solutions were prepared. The initial $\mathrm{pH}$ of the MG solutions was adjusted to the range of $\mathrm{pH} 2-10$ by adding a few drops of $\mathrm{HCl}$ or $\mathrm{NaOH}$ of different concentrations $(0.1 \mathrm{M}-0.5$ $\mathrm{M})$ prior to the experiment. The step above was repeated by using the $\mathrm{Pb}(\mathrm{II})$ solutions with the $\mathrm{pH}$ range from 2 to 5 and the concentration is $10 \mathrm{mg} / \mathrm{L}$. In order to study the role of carboxyl groups in the adsorption of $\mathrm{MG}$ and $\mathrm{Pb}(\mathrm{II})$, OPFF was subjected to esterification. The esterification of carboxyl groups on OPFF was carried out via acidic methanol method with slight modification [19].

The effect of initial concentrations and contact time experiments were studied by using $M G$ and $\mathrm{Pb}$ (II) solutions with various concentrations. The samples were withdrawn and analyzed for their $\mathrm{MG}$ and $\mathrm{Pb}(\mathrm{II})$ concentrations at predetermined intervals $(1,3,5,7,9,15,30,60,120,180,240$ and 300 minutes). Adsorption isotherms were obtained by varying the $\mathrm{Pb}(\mathrm{II})$ concentration from 10 to $50 \mathrm{mg} / \mathrm{L}$ whereas for the $M G$ is from 50 to $130 \mathrm{mg} / \mathrm{L}$.

\section{ACKNOWLEDGEMENTS}

The financial support and research facilities by Universiti Tunku Abdul Rahman are acknowledged.

\section{REFERENCES}

1. J.W. Lee, S.P. Choi, R. Thiruvenkatachari, W.G. Shim, H. Moon, Dyes and Pigments, 2006, 69, 196.

2. S.N. Jain, Z. Shaikh, V.S. Mane, S. Vishnoi, V.N. Mawal, O.R. Patel, P.S. Bhandari, M.S. Gaikwad, Microchem. J., 2019,148, 605.

3. W.H. Cheung, Y.S. Szeto, G. McKay, Bioresource Technol., 2008, 100, 1143.

4. Ş. Parlayici, J. Anal. Sci.Technol., 2019, 10:4.

5. K. Hunger (ed.), "Industrial Dyes: Chemistry, Properties, Applications", Wiley$\mathrm{VCH}$, Weinheim, 2003, chapter 2.

6. S.T. Ong, S.Y. Tan, E.C. Khoo, S.L. Lee, S.T. Ha, Desalin. Water Treat. J., 2012, 45, 161. 
7. S. Bera, V.P. Sharma, S. Dutta, D. Dutta, J. Taiwan Inst. Chem. Eng., 2016, 67, 271.

8. R. Bagheri, M. Ghaedi, A. Asfaram, E.A. Dil, H. Javadian, Polyhedron, 2019, 171, 464.

9. J. Yu, L. Zhang, B. Liu, Int. J. Environ. Res.Public Health, 2019, 16, 3297.

10. S.T. Ong, S.T. Ong, Y.T. Hung, Y.P. Phung, Desalin. Water Treat. J., 2015, 55, 1359.

11. P.P. Kwan, S. Banerjee, M. Shariff, F. Md.Yusoff, Food Control, 2020, 108, 106866.

12. P.S. Keng, S.L. Lee, S.T. Ha, Y.T. Hung, S.T. Ong, Environ. Chem. Lett., 2014, 12, 15.

13. S.T. Ong, Y.C. Foo, Y.T. Hung, Res. J. Chem. Environ., 2013, 17, 53.

14. M.S. Mohamad Amran, M. Dalia Khalid, E. A. Al-Maamary, J. Adv. Sci. Eng. Res., 2011, 1, 76.

15. H.Y. Gan, L.E. Leow, S.T. Ong, Acta Chimica Slovenica, 2017, 64, 144.

16. J.S. Noh, J.A. Schwarz, Great Britain, 1990, 28, 675.

17. F.I. Morais, A.L. Page, L.J. Lund, Soil Sci. Soc. America J., 1976, 40, 521.

18. W. Saikaew, P. Kaewsarn, Songklanakarin J. Sci. Technology, 2009, 31, 547.

19. J.L. Gardea-Torresdey, J. Hazard. Materials, 1999, B80, 175.

20. S. Lagergren, Handlingar, 1898, 24, 1.

21. Y.S. Ho, G. McKay, Process Biochemistry, 1999, 34, 451.

22. H.J. Lee, S.T. Ong, Environ. Protect. Eng., 2017, 43, 169.

23. D.K. Venkata Ramana, Chem. Eng. J., 2012, 197, 24.

24. H. Tang, W.J. Zhou, L. Zhang, J. Hazard. Mat., 2012, 209, 218.

25. Y.S. Ho, G. McKay, Water Research, 2000, 34, 735.

26. I. Langmuir, J. Am. Chem. Soc., 1916, 38, 2221.

27. H.M.F. Freundlich, J. Phys. Chem., 1906, 57, 385.

28. S. Brunauer, P.H. Emmett, E. Teller, J. Am. Chem. Soc., 1938, 60, 309. 